\title{
Medical Image of the Week: Bronchopulmonary Sequestration
}

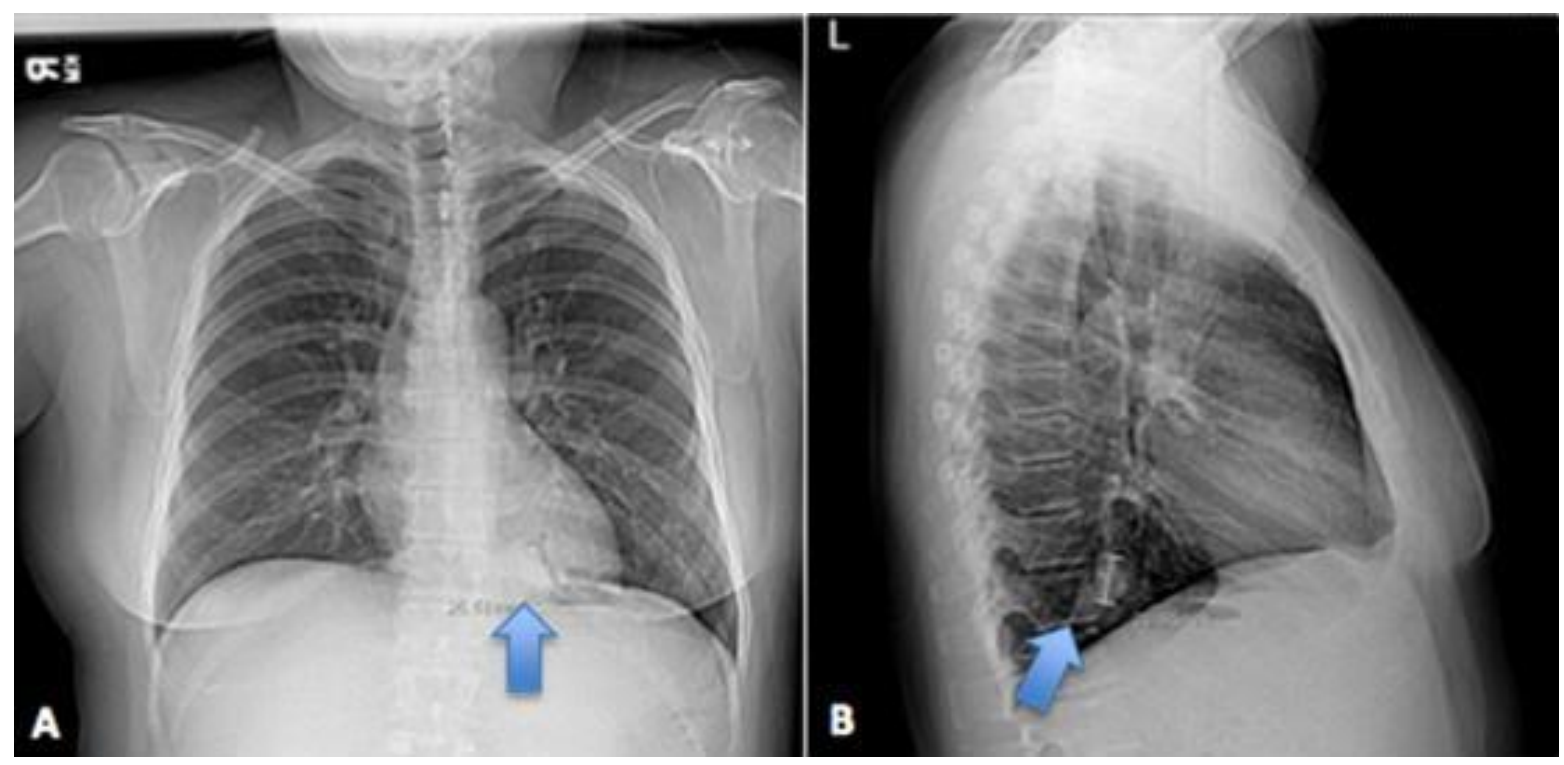

Figure 1. A) Chest $x$-ray PA view demonstrating an oblong soft tissue density in the retrocardiac region overlying the medical aspect of the left hemidiaphragm. $B$ ) Chest $\mathrm{x}$-ray lateral view demonstrating the same opacity anterior to a lower thoracic vertebral body, suspicious for a lung mass.

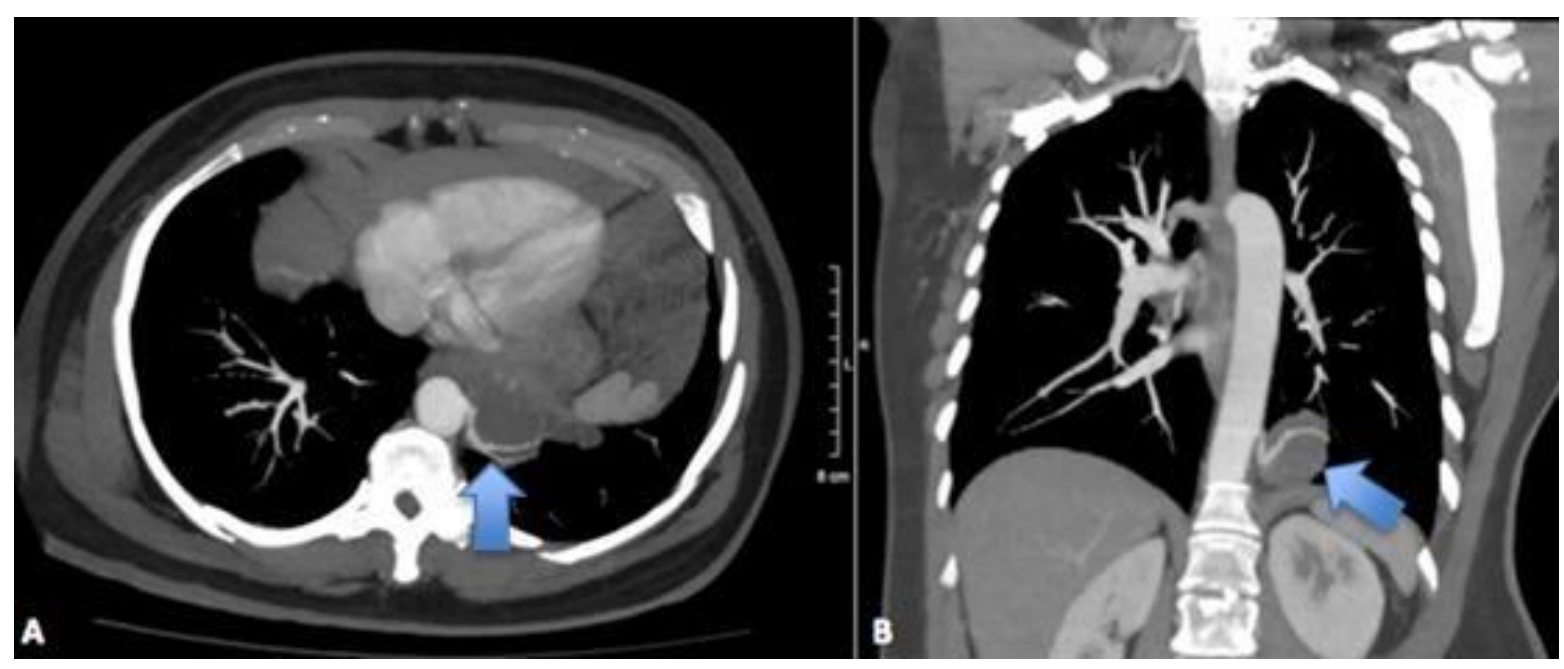

Figure 2. Chest computed tomography A) axial and B) coronal sections demonstrating a lobulated, cystic structure within the left lower lobe with a feeding artery off the aorta, consistent with a pulmonary sequestration.

A 49-year-old woman was incidentally found to have a lung mass on a pre-operative chest $\mathrm{x}$-ray done prior to an elective cholecystectomy (Figure 1). Chest computed tomography, ordered to further characterize this mass revealed a left lower lobe lobulated, cystic opacity with a feeding artery from the aorta, consistent with 
bronchopulmonary sequestration (BPS) (Figure 2). Given that she has not had any complications of BPS we elected to manage her conservatively with observation.

BPS is a rare congenital malformation of the lower airways characterized by abnormal lung tissue that does not communicate with the tracheobronchial tree and receives its blood supply from the systemic circulation (1). Our patient's BPS was intralobar in location, occurring within a normal lobe but lacking its own visceral pleura. The posterior basal left lower lobe is the most common intralobar location. Among cases that escape clinical detection in infancy, BPS comes to light in childhood or adulthood as either an incidental radiographic finding or as a symptomatic presentation of a lung infection. While surgical resection is generally considered to be the treatment of choice given the risk of developing infection, hemorrhage or malignancy (2), some asymptomatic adults with BPS may be managed conservatively with observation with serial imaging (3).

Udit Chaddha MD¹, Niusha Damaghi MD', Ashley Prosper $\mathrm{MD}^{2}$, and Ching-Fei Chang MD ${ }^{1}$

${ }^{1}$ Division of Pulmonary, Critical Care and Sleep Medicine and ${ }^{2}$ Department of Radiology Keck School of Medicine University of Southern California Los Angeles, CA USA

\section{References}

1. Biyyam DR, Chapman T, Ferguson MR, Deutsch G, Dighe MK. Congenital lung abnormalities: embryologic features, prenatal diagnosis, and postnatal radiologicpathologic correlation. Radiographics. 2010 Oct;30(6):1721-38. [CrossRef] [PubMed]

2. Azizkhan RG, Crombleholme TM. Congenital cystic lung disease: contemporary antenatal and postnatal management. Pediatr Surg Int. 2008 Jun;24(6):643-57. [CrossRef] [PubMed]

3. Stanton M, Njere I, Ade-Ajayi N, Patel S, Davenport M. Systematic review and meta-analysis of the postnatal management of congenital cystic lung lesions. $J$ Pediatr Surg. 2009 May;44(5):1027-33. [CrossRef] [PubMed] 